\title{
Comparison of the neuroendocrine and inflammatory responses after laparoscopic and abdominal hysterectomy
}

\author{
Tae Kwane Kim, and Jun Rho Yoon \\ Department of Anesthesiology and Pain Medicine, College of Medicine, The Catholic University of Korea, Bucheon, Korea
}

Background: Laparoscopic surgery is associated with a more favorable clinical outcome than that of conventional open surgery. This might be related to the magnitude of the tissue trauma. The aim of the present study was to examine the differences of the neuroendocrine and inflammatory responses between the two surgical techniques.

Methods: Twenty-four patients with no major medical disease were randomly assigned to undergo laparoscopic $(\mathrm{n}=13)$ or abdominal hysterectomy $(\mathrm{n}=11)$. Venous blood samples were collected and we measured the levels of interleukin-6 (IL-6), CRP and cortisol at the time before and after skin incision, at the end of peritoneum closure and at $1 \mathrm{~h}$ and $24 \mathrm{~h}$ after operation.

Results: The laparoscopic hysterectomy group demonstrated less of an inflammatory response in terms of the serum IL-6 and CRP responses than did the abdominal hysterectomy group, and the laparoscopic hysterectomy group had a shorter hospital stay $(\mathrm{P}<0.05)$. The peak serum IL-6 $(\mathrm{P}<0.05)$ and CRP concentrations were significantly less increased in the laparoscopic group as compared with that of the abdominal hysterectomy group $(\mathrm{P}<0.05)$, while the serum cortisol concentration showed a similar time course and changes and there were no significant difference between the groups. The response of interleukin- 6 showed a significant correlation with the response of CRP $(r=0.796$; $\mathrm{P}<0.05)$.

Conclusions: The laparoscopic surgical procedure leaves the endocrine metabolic response largely unaltered as compared with that of open abdominal hysterectomy, but it reduces the inflammatory response as measured by the IL-6 and CRP levels. (Korean J Anesthesiol 2010; 59: 265-269)

Key Words: Cytokines, Hysterectomy, Interleukine-6, Laparoscopy, Surgical procedures.

Received: February 26, 2010. Revised: 1st, June 16, 2010; 2nd, June 24, 2010. Accepted: July 2, 2010.

Corresponding author: Jun Rho Yoon, M.D., Department of Anesthesiology and Pain Medicine, College of Medicine, The Catholic University of Korea, 2, Sosa-dong, Wonmi-gu, Bucheon 420-717, Korea. Tel: 82-32-340-7075, Fax: 82-32-340-2255, E-mail: pauly@catholic.ac.kr This work was supported by the Institute of Clinical Medicine Research of Bucheon St.Mary's Hospital, Research Fund.

(c) This is an open-access article distributed under the terms of the Creative Commons Attribution Non-Commercial License (http:// creativecommons.org/licenses/by-nc/3.0/), which permits unrestricted non-commercial use, distribution, and reproduction in any medium, provided the original work is properly cited. 


\section{Introduction}

Surgical trauma, and particularly the surgical trauma associated with major operations, elicits characteristic profound physiologic changes that involve the metabolic (neuroendocrine), inflammatory and immune reactions that lead to wide spread changes in the functioning of body organs. This overall effect is commonly referred to as the stress response to surgery [1-3]. The magnitude of the stress response is roughly proportional to the severity of surgery and this has an influence on the postoperative complications and the patients' convalescence and morbidity [3]. Therefore, many investigators have attempted to find ways to attenuate the stress response to surgery [4].

Laparoscopic surgery is becoming more popular and it is rapidly replacing conventional open surgery for the same procedure. In contrast to conventional open surgery, laparoscopic surgery is associated with reduced postoperative pain, a reduced hospital stay and a rapid return to normal activity $[5,6]$. Although laparoscopic procedures results in a favorable clinical outcome compared with open surgical procedures, little is known about their impact on improving the clinical outcome and homeostasis, and especially in the gynecologic field.

This study was designed to investigate the differences of the inflammatory markers IL-6 and C-reactive protein (CRP) and the neuroendocrine response between laparoscopy and open surgery for performing total hysterectomy.

\section{Materials and Methods}

The study was conducted after receiving approval from the hospital's ethical committee, and informed, written content was obtained from all the patients. Twenty four ASA I and II patients and who were scheduled for elective total hysterectomy for nonmalignant disease were studied preoperatively and for 24 hours after their operations. The patients were randomly allocated to receive either an abdominal hysterectomy or laparoscopic assisted hysterectomy for their benign disease. All the patients had no anemia, chronic inflammatory disease, metabolic or endocrine disorder, hepatic disease or renal disease, and they were not receiving any medications.

All patients were premedicated with an intravenous injection of glycopyrrolate $0.2 \mathrm{mg}$ before arrival in the operating room and all the patients were placed under general anesthesia along with performing endotracheal intubation. Anesthesia was induced with an IV bolus of thiopental sodium $(5 \mathrm{mg} / \mathrm{kg}$ ) or propofol $(2 \mathrm{mg} / \mathrm{kg})$, and tracheal intubation was facilitated with IV rocuronium bromide (esmeron ${ }^{\circledR} 0.08 \mathrm{mg} / \mathrm{kg}$ ). Anesthesia was maintained with inhalation of sevoflurane in $40 \% \mathrm{O}_{2}$ in air and the patients were ventilated to maintain an end tidal $\mathrm{PaCO}_{2}$ of $35-45 \mathrm{mmHg}$.

Venous blood samples were collected from each patient at the following times: a baseline sample before surgery (T0), after skin incision (T1), at the end of peritoneum closure (T2), $1 \mathrm{~h}$ after the operation (T3) and $24 \mathrm{~h}$ after the operation (T4). The samples were separated and the sera were all stored at $-80^{\circ} \mathrm{C}$ until analysis for the cortisol and IL-6 levels. The IL-6 in the serum was analyzed using a commercially available enzymelinked immunosorbent assay (ELISA) method (IL-6 Quantikan kit; R \& D systems, Minneapolis, MN, USA) with a detection limit of $0.3 \mathrm{pg} / \mathrm{ml}$. The serum cortisol was determined by radioimmunoassay (Gamma Coat ${ }^{\mathrm{TM}}$ Cortisol Kit; Diasorin Inc. Stillwater. MN, USA) with a sensitivity of $0.21 \mu \mathrm{g} / \mathrm{dl}$ (normal reference range: $7-25 \mu \mathrm{g} / \mathrm{dl}$ ). The C-reactive protein (CRP) was measured by an immunoturbidimetric assay (Roche Diagnostics, IN, USA). The detection limit of this assay was 0.425 $\mathrm{mg} / \mathrm{L}$.

Statistical analysis was performed using Sigmastat (version 2.03, SPSS, Chicago, IL). The changes in the IL-6, CRP and cortisol concentrations over time within and between the groups were analyzed using two-way repeated measures of ANOVA. The hospital days were analyzed using unpaired student's t-tests. The correlation between IL-6 and CRP was analyzed using Pearson's correlation coefficient. All the values were expressed as means \pm SEMs. P values $<0.05$ were considered to be significant.

\section{Results}

There was no difference between the two groups with respect to age, weight, the operation time and the duration of anesthesia. The characteristics of the patients who underwent laparoscopy or conventional open surgery are summarized in Table 1. None of the patients required a blood transfusion during or after surgery. The mean duration of surgery was

Table 1. Patients' Characteristics and the Clinical Variables

\begin{tabular}{lcc}
\hline & $\begin{array}{c}\text { Laparoscopy } \\
(\mathrm{n}=13)\end{array}$ & $\begin{array}{c}\text { Laparotomy } \\
(\mathrm{n}=11)\end{array}$ \\
\hline Age (yr) & $44.5 \pm 3.1$ & $45.4 \pm 8.4$ \\
Weight (kg) & $58.1 \pm 5.9$ & $60.0 \pm 8.2$ \\
Height (cm) & $158.5 \pm 3.3$ & $156.2 \pm 3.7$ \\
Duration of surgery (min) & $141.4 \pm 41.5$ & $122.7 \pm 11.2$ \\
Duration of anesthesia (min) & $188.61 \pm 37.9$ & $151.8 \pm 14.1$ \\
Hospital day (days) & $5.6 \pm 0.5$ & $7.9 \pm 0.2^{*}$ \\
\hline
\end{tabular}

Values are means \pm SEMs. There were no significant differences between the groups, but the laparoscopic hysterectomy group showed a significantly shorter hospital stay as compared with that of the abdominal hysterectomy group. ${ }^{*} \mathrm{P}<0.05$ compared with abdominal hysterectomy. 
$141.4 \pm 41.5 \mathrm{~min}$ for laparoscopic surgery and $122.7 \pm 11.2$ min for abdominal hysterectomy, but there was no significant difference. The duration of the postoperative hospital stay for the patients who underwent laparoscopic hysterectomy was $5.6 \pm 0.5$ days as compared to $7.9 \pm 0.2$ days for the patients who underwent abdominal hysterectomy $(\mathrm{P}<0.05)$.

Before operation, the serum IL-6 level was not detected in both groups. However, the levels of IL-6 rose significantly after surgery in both groups. As the surgery proceeded, the changes of IL-6 showed a similar pattern between the groups: the level increased at the end of peritoneum closure and it reached the peak value at $1 \mathrm{hr}$ postoperatively. For the patients

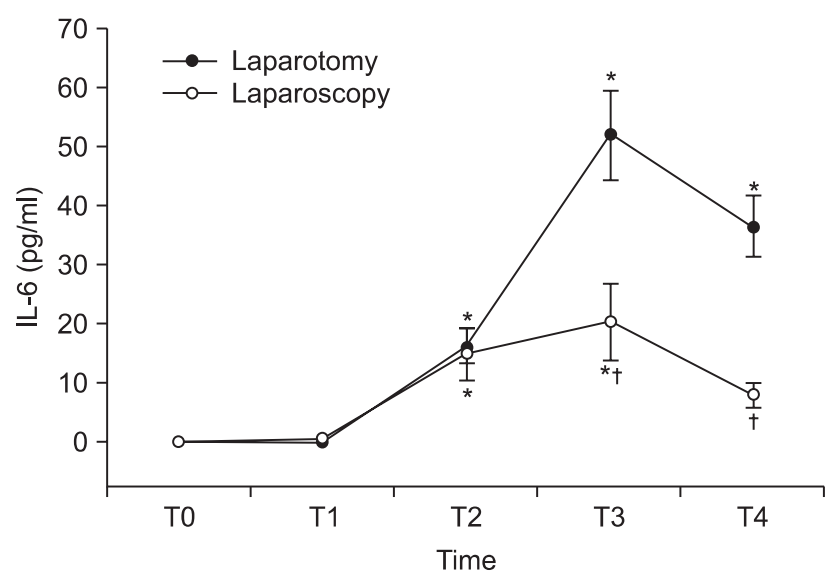

Fig. 1. Changes in the plasma IL-6 concentration (mean \pm SEM) during and after laparoscopic and abdominal hysterectomy. Measurement points: $\mathrm{T} 0=$ before anesthesia, $\mathrm{T} 1=$ after skin incision, $\mathrm{T} 2=$ at the end of peritoneal closure, $\mathrm{T} 3=1 \mathrm{~h}$ after operation, $\mathrm{T} 4=24$ $\mathrm{h}$ after operation. ${ }^{*} \mathrm{P}<0.05$ versus the preoperative value. ${ }^{\dagger} \mathrm{P}<0.05$ versus abdominal hysterectomy.

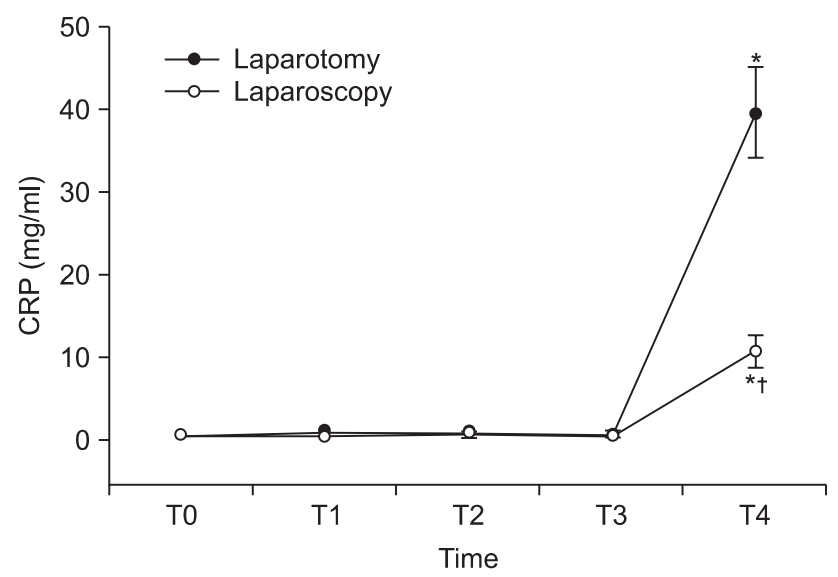

Fig. 2. Changes in the plasma CRP concentration (mean \pm SEM) during and after laparoscopic and abdominal hysterectomy. Measurement points: $\mathrm{T} 0=$ before anesthesia, $\mathrm{T} 1=$ after skin incision, $\mathrm{T} 2=$ st the end of peritoneal closure, $\mathrm{T} 3=1 \mathrm{~h}$ after operation, $\mathrm{T} 4=24$ $\mathrm{h}$ after operation. ${ }^{*} \mathrm{P}<0.05$ versus the preoperative value. ${ }^{\dagger} \mathrm{P}<0.05$ versus abdominal hysterectomy. who underwent abdominal hysterectomy, the peak IL-6 concentration was significant higher than the peak IL-6 levels of the patients who underwent laparoscopic hysterectomy (P $<0.05$ ). The IL-6 level in the abdominal hysterectomy group remained significantly elevated for $24 \mathrm{hr}$ postoperatively, and this was longer than that in the laparoscopic hysterectomy group ( $\mathrm{P}<0.05$, Fig. 1$)$.

Fig. 2 shows the response of the CRP level to surgery in both the groups. The serum concentration of CRP did not increase throughout the operation or at $1 \mathrm{hr}$ postoperatively, but there was an abrupt significantly higher increase at $24 \mathrm{hr}$ after the operation in both groups. The mean CRP concentration at $24 \mathrm{hr}$ postoperatively was $10.8 \mathrm{mg} / \mathrm{L}$ in the patients who underwent laparoscopic hysterectomy as compared to that of the patients who underwent abdominal hysterectomy $(39.5 \mathrm{mg} / \mathrm{L})(\mathrm{P}<0.05)$ and there was correlation with between the cytokine and CRP levels (Pearson correlation coefficient $\mathrm{r}=0.796$; $\mathrm{P}<0.05$ ).

For the serum cortisol level, the baseline serum cortisol level was no difference between the groups and the groups had similar sequential changes over time throughout the operation and $24 \mathrm{hr}$ after operation. The serum cortisol level increased after the surgery started, it reached its peak level at $1 \mathrm{hr}$ postoperatively in the patients undergoing abdominal hysterectomy, but it reached its peak level at the end of peritoneum closure in the patients who were undergoing laparoscopic hysterectomy. Although the serum cortisol level did not show a significant difference between the groups, more rapid decline to baseline (from $30.4 \pm 7.7 \mu \mathrm{g} / \mathrm{dl}$ to $11.8 \pm 3.6 \mu \mathrm{g} / \mathrm{dl}$ ) after operation and from $38.0 \pm 14.3 \mu \mathrm{g} / \mathrm{dl}$ to $18.1 \pm 5.9 \mu \mathrm{g} / \mathrm{dl}$ in the patients who underwent abdominal hysterectomy. But there was no significant difference for this between the groups (Fig. 3).

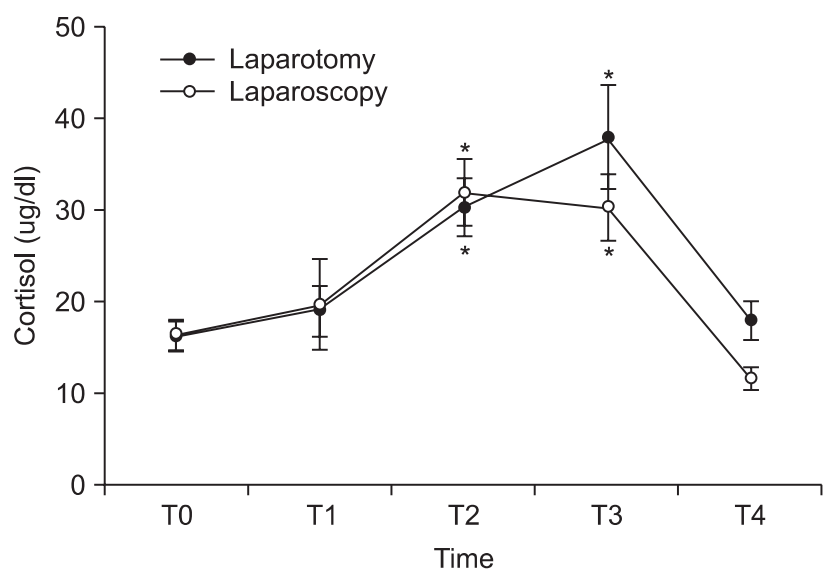

Fig. 3. Changes in the plasma cortisol concentration (mean \pm SEM) during and after laparoscopic and abdominal hysterectomy. Measurement points: T0 = before anesthesia, T1 = after skin incision, $\mathrm{T} 2=$ at the end of peritoneal closure, $\mathrm{T} 3=1 \mathrm{~h}$ after operation, $\mathrm{T} 4=24$ $\mathrm{h}$ after operation. ${ }^{*} \mathrm{P}<0.05$ versus the preoperative value. 


\section{Discussion}

This present study demonstrated that laparoscopic hysterectomy induced less tissue trauma and less of an inflammatory response than did open abdominal hysterectomy. Moreover, our results suggested that the surgical technique we employed has a capability to modify the extent of surgical trauma.

Surgical trauma, especially a major operation, stimulates a series of hormonal, metabolic and inflammatory changes that constitute the stress response [1-3]. This surgical stress response occurs through the activation of the afferent neural and sympathetic nervous systems and biological potent inflammatory mediators, e.g., cytokine [7-9]. Of all the proinflammtory cytokines, IL-6 is the main mediator that is released with surgical injury and it has an early and important role to play in the local and systemic inflammatory response. According to several studies, including the study by Cruickshank et al. [8], IL-6 is directly proportional to the extent of the direct surgical tissue injuries and the duration of the operation. The concentration of this mediator entering the systemic circulation is correlated with the magnitude of the tissue injury. Thus, it can be a useful maker for comparing different surgical methods that are applied for the same purpose [9].

In the present study, the serum IL-6 level was not detected in both groups before and immediately after surgery. As the surgery proceeded, the serum IL- 6 began to increase with delay at the end of peritoneum closure, and it reached its peak value at $1 \mathrm{~h}$ postoperatively. But the serum concentration of IL-6 was less marked and it showed a more prompt return toward baseline values following laparoscopic hysterectomy as compared to that following abdominal hysterectomy. This finding showed that the surgical trauma related with a skin incision can trigger cytokine to be released from injured tissue, and laparoscopic surgery is associated with less tissue injury and less inflammation than that of abdominal hysterectomy. This decreased IL-6 response following laparoscopic surgery are probably due to avoiding a larger surgical wound and the lesser intra-abdominal tissue damage that is secondary to intraoperative manipulation and incision of exposed tissue [10].

These findings of our study are consistent with those of the previous studies [10-12], showing that laparoscopic surgical technique induces less of an inflammatory response than that of open surgery. But several studies have failed to find any difference when comparing the two surgical techniques. Ellströme et al. [13] demonstrated that there were no significant differences in the serum IL-6 and CRP concentrations in the patients who underwent laparoscopic and abdominal hysterectomy. They reported the extent of surgical trauma did not differ between the two operative techniques. They concluded that this lack of difference could be attributed to the significantly longer operation time of laparoscopic surgery, which might have obscured the benefits of less tissue trauma. In our study, the same anesthetic methods and agents were administered and the surgery time was not significantly longer for laparoscopic surgery. The only difference was the type of surgical procedure. This finding supports that the severity and extent of the trauma are more important than the operating time per se, like what was reported by Kristiansson et al. [14]. This concept, that tissue damage is the key determinant of recovery, is supported by the studies in which the length of the abdominal incisions was varied [15] and by the studies that used smaller laparoscopic ports [16].

The host responses that follow surgical injury, such as fever, leukocytosis and synthesis of acute-phase proteins restore homeostasis and promote wound healing. These acute and intermediate responses are called the acute phase reaction $[17,18]$. CRP, as a key representative of the acute-phase proteins, reflects that the magnitude of the metabolic response to surgical trauma is proportional to the degree of injury [17]. In our study, the response of IL- 6 preceded the response of CRP, and the former showed a clear increase $24 \mathrm{hr}$ after surgery in the laparotomy group and there was significant correlation between the IL-6 level and the CRP level. This finding supported the fact that the cytokine IL-6 is the primary stimulus for the acutephase response [17].

Elevated serum cortisol levels are indicative of surgical stress $[19,20]$. In the present study, both the laparoscopic and open surgical approaches caused an increased serum cortisol level. The similarity in the cortisol response between the two groups suggests that laparoscopic hysterectomy, despite the absence of a substantial abdominal incision, cause a significant stress response similar to that resulting from abdominal hysterectomy. The increased cortisol level following the laparoscopic surgical technique indicate that a considerable activation of the neuroendocrine response occurs after laparoscopic surgery despite the absence of a substantial skin incision. It also suggests that the main stimuli for promoting hormonal secretion are visceral and peritoneal afferent activities and not the stimuli arising from the abdominal wall. This was supported by the prompt fall of the serum cortisol level soon after peritoneal deflation.

In conclusion, our study demonstrated that laparoscopic hysterectomy did not greatly alter the classic neuroendocrine response, but laparoscopic hysterectomy is associated with a less intense inflammatory response compared with that of abdominal hysterectomy. Laparoscopic surgery is believed to lessen the surgical trauma and so it causes redcued disturbance of the physiologic function. This may all contribute to the rapid recovery after laparoscopic hysterectomy. 


\section{References}

1. Desborough JP. The stress response to trauma and surgery. Br J Anaesth 2000; 85: 109-17.

2. Buunen M, Gholghesaei M, Velldkamp R, Meijer DW, Bonjer HJ, Bouvy ND. Stress response to laparoscopic surgery: a review. Surg Endosc 2004; 18: 1022-8.

3. Sylla P, Kirman I, Whelan RL. Immunological advantages of advanced laparoscopy. Surg Clin North Am 2005; 85: 1-18.

4. Kehlet H, Wilmore DW. Multimodal strategies to improve surgical outcome. Am J Surg 2002; 183: 630-41.

5. Song SO. Anesthetic management for laparoscopic cholecystectomy. Korean J Anesthesiol 2004; 47: 1-11.

6. Farrar MW, Hall GM. Neuroendocrine and inflammatory aspects of surgery: do they affect outcome? Eur J Anaesthesiol 1998; 15: 736-9

7. Biffl WL, Moore EE, Moore FA, Peterson VM. Interlleukin-6 in the injured patient; marker of injury or mediator of inflammation? Ann Surg 1996; 224: 647-64.

8. Cruickshank AM, Fraser WD, Burns HJ, Van Damme J, Shenkin A. Response of serum interleukin- 6 in patients undergoing electivesurgery of varying severity. Clin Sci 1990; 79: 161-5.

9. Maruszynski M, Pojda Z. Interleukin 6 (IL-6) levels in the monitoring of surgical trauma: a comparison of serum IL-6 concentration in patients treated by cholecystectomy via laparotomy or laparoscopy. Surg Endosc 1995; 9: 882-5.

10. Yuen PM, Mak TW, Yim SF, Kee WD, Lam CW, Rogers MS, et al. Metabolic and inflammatory responses after laparospic and abdominal hysterectomy. Am J Obstet Gynecol 1998; 179: 1-5.

11. Joris J, Cigarine I, Legrand M, Jacquet N, de Groote D, Franchimont $\mathrm{P}$, et al. Metabolic and respiratory changes after cholecystectomy performed via laparotomy or laparoscopy. Br J Anaesth 1992; 69: 341-5.
12. Harkki-Siren P, Sjöberg J, Toivonen J, Tiitienen A. Clinical outcome and tissue trauma after laparoscopic and abdominal hysterectomy. Acta Obstet Gynecol Scand 2000; 79: 866-71.

13. Ellström M, Bengtsson A, Tylman M, Haeger M, Olsson JH, Hahlin M. Evaluation of tissue trauma after laparoscopic and abdominal hysterectomy: measurement of neutrophils activation and release of interleukin-6, cortisol, and C-reactive protein. J Am Coll Surg 1996; 182: 423-30.

14. Kristiansson M, Saraste L, Soop M, Sundqvist KG, Thörne A. Diminished interleukin-6 and C-reactive protein responses to laparoscopic verus open cholecystectomy. Acta Anaesthesiol Scand 1999; 43: 146-52.

15. O'Dwyer PJ, McGregor JR, McDermott EW, Murphy JJ, O'Higgins NJ. Patient recovery following cholecystectomy through a $6 \mathrm{~cm}$ or $15 \mathrm{~cm}$ transverse subcostal incison: a prospective randomized clinical trial. Postgrad Med J 1992; 68: 817-9.

16. Matsuda T, Ogura K, Uchida J, Fujita I, Terachi T, Yoshida O. Smaller ports results in shorter convalescence after laparoscopic varicocelectomy. J Urol 1995; 153: 1175-7.

17. Heinrich PC, Castell JV, Andus T. Interleukin- 6 and the acute phase response. Biochem J 1990; 265: 621-36.

18. Baigrie RJ, Lamont PM, Kwiatkowski D, Dallman MJ, Morris PJ. Systemic cytokine response after major surgery. Br J Surg 1992; 79: 757-60.

19. Matsumoto ED, Margulis V, Tunc L, Taylor GD, Duchene D, Johnson DB, et al. Cytokine response to surgical stress: comparison of pure laparoscopic, hand-assisted laparoscopic, and open nephrectomy. J Endourol 2005; 19: 1140-5.

20. Aldana JP, Marcovich R, Singhal P, Reddy K, Morgenstrern N, ElHakim A, et al. Immune response to laparoscopic bowel injury. J Endourol 2003; 17: 317-22. 